\title{
Erratum to: Should Mild COPD Be Treated? Evidence for Early Pharmacological Intervention
}

\author{
Amany F. Elbehairy - Katherine A. Webb •
}

J. Alberto Neder · Denis E. O'Donnell

Published online: 19 December 2013

(C) Springer International Publishing Switzerland 2013

Erratum to: Drugs (2013) 73:1991-2001

DOI 10.1007/s40265-013-145-9

Title page: author affiliations which previously read
A. F. Elbehairy
K. A. Webb . J. Alberto Neder .

D. E. O’Donnell

should read:
A. F. Elbehairy
K. A. Webb . J.
A. Neder .
D. E. O’Donnell

The third author's given names are J. Alberto and his family name is Neder.

The online version of the original article can be found under doi:10.1007/s40265-013-0145-9.

\footnotetext{
A. F. Elbehairy $(\bowtie) \cdot$ K. A. Webb · J. A. Neder .

D. E. O'Donnell

Division of Respiratory and Critical Care Medicine, Department of Medicine, Queen's University, 102 Stuart Street, Kingston,

ON K7L 2V6, Canada

e-mail: odonnell@post.queensu.ca; odonnell@queensu.ca
}

A. F. Elbehairy

Department of Chest Diseases, Faculty of Medicine,

Alexandria University, Alexandria, Egypt 